\title{
TEORES FOLIARES DE NUTRIENTES NO MARACUJAZEIRO AMARELO EM FUNÇÃO DE ADUBAÇÃO NITROGENADA, IRRIGAÇÃO E EPÓCAS DE AMOSTRAGEM
}

\author{
Almy Junior Cordeiro de Carvalho1*; Pedro Henrique Monnerat ${ }^{1}$; Donivaldo Pedro Martins²; \\ Salassier Bernardo; José Accácio da Silva ${ }^{1}$ \\ ${ }^{1}$ CCTA/LFIT - UENF, Av. Alberto Lamego, 2000 - CEP: 28015-620 - Campos dos Goytacazes, RJ. \\ 2 IICA/INCRA, SBN Edf. Palácio do Desenvolvimento SI 907, CEP: 70873-020 - Brasília, DF. \\ *Autor correspondente <almy@uenf.br>
}

\begin{abstract}
RESUMO: A realização de diagnósticos de culturas, através do conhecimento dos teores foliares dos nutrientes, em cada condição de cultivo, se justifica e tem por finalidade corrigir deficiências, inclusive com a utilização de ferramentas tais como o DRIS (Sistema Integrado de Diagnose e Recomendação), que auxiliam no manejo para a obtenção de altos rendimentos das culturas. Este trabalho teve por objetivo avaliar os efeitos da adubação nitrogenada, irrigação e época de amostragem nos teores dos nutrientes foliares na cultura do maracujazeiro amarelo (Passiflora edulis f. flavicarpa). O experimento foi conduzido em Campos-RJ, em Argissolo Amarelo distrófico, onde foram combinadas quatro doses de nitrogênio (50 a $650 \mathrm{~g}$ por planta por ano de N) com 6 lâminas de irrigação (0 a 125\% da ETo - Evapotranspiração de referência). Na maior produtividade de frutos $\left(41,3 \mathrm{t} \mathrm{ha}^{-1}\right)$, os teores de nutrientes foliares variaram de 40,8 a $58,1 \mathrm{~g} \mathrm{~kg}^{-1}$ de N, 2,58 a 3,85 g kg-1 de P, 23,2 a $38 \mathrm{~g} \mathrm{~kg}^{-1}$ de K, 6,13 a 14,4 $\mathrm{g} \mathrm{kg}^{-1}$ de Ca, 2,23 a 4,28 g kg-1 de Mg, 3,2 a 4,64 g kg-1 de S, 13,1 a $32,4 \mathrm{~g} \mathrm{~kg}^{-1}$ de Cl, 21,1 a $36,5 \mathrm{mg} \mathrm{kg}^{-1}$ de Zn, 44,4 a 94,5 mg kg-1 de Mn, 82 a $246 \mathrm{mg} \mathrm{kg}^{-1} \mathrm{de} \mathrm{Fe}^{-}$ 16,8 a 48,9 mg kg-1 de B e 3,97 a $234 \mathrm{mg} \mathrm{kg}^{-1}$ de $\mathrm{Cu}$. A adubação nitrogenada afetou os teores foliares de $\mathrm{N}$, $\mathrm{K}, \mathrm{S}, \mathrm{Ca}, \mathrm{Mg}, \mathrm{Mn}, \mathrm{Cl}$ e B. A irrigação elevou os teores foliares de $\mathrm{Cl}$ e de $\mathrm{Na}$ e não influenciou nos teores foliares dos outros nutrientes.
\end{abstract}

Palavras-chave: Passiflora, fertilização, maracujá, nitrogênio, nutriente foliar

\section{LEAF NUTRIENT CONTENTS IN YELLOW PASSIONFRUIT IN RESPONSE TO NITROGEN FERTILIZATION, IRRIGATION AND SAMPLING TIME}

\begin{abstract}
Crop diagnosis with knowledge of leaf nutrient contents, for each cultivation condition, is justified and has the purpose of correcting nutrient deficiencies, as well as the use of tools like DRIS (Diagnosis and Recommendation Integrated System), that help management practices to obtain high productivity. The objective of this work was evaluate the effect of nitrogen fertilization, irrigation and period of the year on the leaf nutrient contents of the yellow passionfruit (Passiflora edulis f. flavicarpa) crop. The experiment was carried in the Rio de Janeiro State, Brazil, on a Rhodic Paleudult, ammended with four nitrogen levels (50 to $650 \mathrm{~g} \mathrm{plant}^{-1}$ year ${ }^{1}$ of $\mathrm{N}$ ) submitted to six irrigation depths ( 0 to $125 \%$ of ETo - reference crop evapotranspiration for grass). The nutrient leaf contents, at maximum fruit yield $\left(41.3 \mathrm{t} \mathrm{ha}^{-1}\right)$, ranged from 40.8 to $58.1 \mathrm{~g} \mathrm{~kg}^{-1}$ of N, 2.58 to $3.85 \mathrm{~g}$ $\mathrm{kg}^{-1}$ of $\mathrm{P}, 23.2$ to $38 \mathrm{~g} \mathrm{~kg}^{-1}$ of $\mathrm{K}, 6.13$ to $14.4 \mathrm{~g} \mathrm{~kg}^{-1}$ of $\mathrm{Ca}, 2.23$ to $4.28 \mathrm{~g} \mathrm{~kg}^{-1}$ of Mg and 3.2 to $4.64 \mathrm{~g} \mathrm{~kg}^{-1}$ of S, 13.1 to $32.4 \mathrm{~g} \mathrm{~kg}^{-1}$ of Cl, 21.1 to $36.5 \mathrm{mg} \mathrm{kg}^{-1}$ of $Z \mathrm{n}, 44.4$ to $94.5 \mathrm{mg} \mathrm{kg}^{-1}$ of Mn, 82 to $246 \mathrm{mg} \mathrm{kg}^{-1}$ of Fe, 16.8 to $48.9 \mathrm{mg} \mathrm{kg}^{-1}$ of B, 3.97 to $234 \mathrm{mg} \mathrm{kg}^{-1}$ of Cu. Nitrogen fertilization influenced leaf contents of $\mathrm{N}, \mathrm{K}, \mathrm{S}, \mathrm{Ca}$, $\mathrm{Mg}, \mathrm{Mn}, \mathrm{Cl}$ and $\mathrm{B}$. Irrigation depth increased the leaf contents of $\mathrm{Cl}$ and $\mathrm{Na}$ and did not affect the other leaf nutrients.
\end{abstract}

Key words: Passiflora, fertilization, passionfruit, nitrogen, leaf nutrient

\section{INTRODUÇÃO}

A avaliação do estado nutricional das culturas constitui um dos maiores desafios para pesquisadores em fertilidade do solo e nutrição de plantas, principalmente em países onde ocorrem limitações na produtividade das culturas decorrentes de desequilíbrios nutricionais. No Brasil, a existência de poucos trabalhos sobre as doses de adubo nitrogenado e a quantidade de água a ser aplicada para a obtenção da máxima produtividade do maracujazeiro e os níveis críticos de nutrientes no solo e na planta para estas condições, fortalece ainda mais a necessidade de se pesquisar tais fatores.
Segundo Menzel et al. (1991), o nitrogênio (N) é o mais importante nutriente no crescimento e desenvolvimento do maracujazeiro, dominando todo o sistema de nutrição da cultura em condições de campo. Trabalhando com um híbrido de maracujazeiro amarelo $x$ maracujazeiro roxo em vasos com areia, estes pesquisadores mostraram que o suprimento de $\mathrm{N}$ teve significativa influência sobre o crescimento vegetativo e reprodutivo da cultura e que o melhor crescimento das plantas está associado com uma concentração foliar de 45 a $55 \mathrm{~g} \mathrm{~kg}^{-1}$ de $\mathrm{N}$ na matéria seca. Aplicações excessivas de $\mathrm{N}$ levaram a decréscimos na produção de folhas e na área foliar, havendo aumento no número de 
flores por ramo, verificando-se uma forte correlação entre o número de nós, o florescimento e o comprimento total dos ramos.

Os níveis adequados de nutrientes encontrados pela análise foliar ainda não foram estabelecidos para o maracujazeiro em suas diversas fases. Porém, alguns autores (Menzel et al., 1993, Malavolta et al., 1989, Robinson, 1986, Aguirre, 1977 e Haag et al., 1973) admitem faixas adequadas para os nutrientes, nas condições em que foram determinadas, observando-se grande variação nas informações apresentadas. Kliemann et al. (1986) explicam que essas divergências podem ser ocasionadas por várias razões, como diferenças na época de amostragem, na parte amostrada, nas variedades, nas condições de desenvolvimento da cultura e no manejo.

Os padrões foliares desenvolvidos preliminarmente para o maracujazeiro não podem ser extrapolados diretamente para pomares comerciais porque os procedimentos de amostragem não foram bem definidos. Muitos autores não consideraram, em seus experimentos, o efeito da estação de crescimento, a idade da folha, o estádio de frutificação e fase fenológica da planta.

Menzel et al. (1993) observaram que as concentrações foliares de $\mathrm{N}, \mathrm{P}$ e $\mathrm{K}$ apresentaram grandes flutuações durante $\mathrm{o}$ ano, entretanto apenas as mudanças na concentração do $\mathrm{K}$ apresentaram diferenças significativas. Ocorreu um declínio na concentração de $\mathrm{N}, \mathrm{P}$ e K após o período de máximo desenvolvimento vegetativo e durante o período de pegamento do fruto, refletindo a mobilização dos nutrientes para o desenvolvimento dos ramos, flores e frutos.

Alguns autores verificaram acúmulos de $B, Z n$, $\mathrm{Cu}$ e $\mathrm{Mn}$ na parte aérea das plantas em função de adubações nitrogenadas. Isso foi observado, para $\mathrm{Mn}$, em goiaba por Natale (1993) e para o Mn, B, Zn e Cu, em milho por Resende et al. (1997) e Thompson (1962).

Os objetivos do presente trabalho foram avaliar os efeitos da adubação nitrogenada e da irrigação, sobre os teores foliares dos nutrientes $\mathrm{N} \mathrm{P}, \mathrm{K}, \mathrm{Ca}, \mathrm{Mg}, \mathrm{S}, \mathrm{Cl}$, $\mathrm{Zn}, \mathrm{Mn}, \mathrm{Fe}, \mathrm{B}, \mathrm{Cu}$ e do elemento mineral $\mathrm{Na}$ em diferentes épocas do desenvolvimento do maracujazeiro amarelo.

\section{MATERIAL E MÉTODOS}

O experimento foi instalado no município de Campos dos Goytacazes, RJ (Latitude $=21^{\circ} 19^{\prime} 23^{\prime \prime}$; Longitude $=41^{\circ} 10^{\prime} 40^{\prime \prime} \mathrm{W}$; Altitude $=14 \mathrm{~m}$ ), em um Argissolo Amarelo distrófico, com camada superficial arenosa, horizonte $B$ textural e relevo suave ondulado. As umidades do solo na capacidade de campo e no ponto de murcha permanente, até a profundidade de $40 \mathrm{~cm}$, foram estimados, através da curva característica de retenção de água no solo, em 130 e $65 \mathrm{~g} \mathrm{~L}^{-1}$ de água,
Tabela 1 - Características climáticas do município de Campos dos Goytacazes-RJ, Brasil

\begin{tabular}{|c|c|c|c|c|c|c|c|c|c|}
\hline \multirow[t]{2}{*}{ Mês } & \multicolumn{2}{|c|}{$\begin{array}{l}\text { Temp. } \\
\text { média }\end{array}$} & \multicolumn{2}{|c|}{ Precipitação } & \multicolumn{2}{|c|}{$\begin{array}{l}\text { Umid. } \\
\text { Relativa }\end{array}$} & \multicolumn{2}{|c|}{$\mathrm{ETo}^{3}$} & \multirow[t]{2}{*}{ Luz } \\
\hline & $A^{1}$ & $\mathrm{~B}^{2}$ & $A^{1}$ & $\mathrm{~B}^{2}$ & $A^{1}$ & $\mathrm{~B}^{2}$ & $A^{1}$ & $\mathrm{~B}^{2}$ & \\
\hline & \multicolumn{2}{|c|}{--- ${ }^{\circ} \mathrm{C}---$} & \multicolumn{2}{|c|}{$\mathrm{mm} \mathrm{mês}^{-1}$} & \multicolumn{2}{|c|}{---- \% --- } & \multicolumn{2}{|c|}{$\mathrm{mm} \mathrm{dia}^{-1}$} & horas $\mathrm{dia}^{-1}$ \\
\hline jan. & 27,1 & 27,2 & 134 & 78 & 76,1 & 75,8 & 5,10 & 5,45 & 13,3 \\
\hline fev. & 27,7 & 28,2 & 82 & 36 & 73,7 & 72,1 & 5,45 & 5,85 & 12,8 \\
\hline mar. & 26,1 & 26,5 & 83 & 140 & 75,9 & 76,8 & 4,60 & 4,02 & 12,2 \\
\hline abr. & 24,0 & 25,0 & 83 & 56 & 77,7 & 74,5 & 3,80 & 3,31 & 11,6 \\
\hline mai. & 22,3 & 22,4 & 54 & 32 & 77,4 & 73,5 & 3,20 & 2,63 & 11,2 \\
\hline jun. & 21,4 & 21,8 & 34 & 17 & 77,2 & 72,3 & 2,69 & 2,46 & 10,8 \\
\hline jul. & 21,4 & 21,3 & 42 & 51 & 74,3 & 73,8 & 2,90 & 2,27 & 10,9 \\
\hline ago. & 22,1 & 21,3 & 30 & 67 & 76,5 & 72,3 & 3,50 & 3,09 & 11,3 \\
\hline set & 22,9 & 21,6 & 57 & 166 & 77,7 & 80,3 & 3,70 & 2,77 & 12,0 \\
\hline out. & 24,3 & 23,0 & 99 & 63 & 77,9 & 79,4 & 4,10 & 4,16 & 12,6 \\
\hline nov. & 25,3 & 24,0 & 153 & 167 & 78,2 & 81,3 & 4,70 & 3,14 & 13,2 \\
\hline dez. & 25,1 & 25,7 & 172 & 122 & 75,6 & 78,3 & 4,70 & 4,48 & 13,4 \\
\hline Média & 24,1 & 24 & 85 & 83 & 76,5 & 75,9 & 4,04 & 3,64 & 12,1 \\
\hline
\end{tabular}

${ }^{1} \mathrm{~A}=$ média de 15 anos (1979-1993); ${ }^{2} \mathrm{~B}=$ média de 2 anos (1996 1997);

${ }^{3} \mathrm{ETo}=$ Evaporação do Tanque Classe $\mathrm{A} \times$ coeficiente do tanque (Bernardo, 1995).

Fonte: UFRRJ (Campus Leonel Miranda) e Estação Evapotranspirométrica - UENF/Pesagro-Rio. Campos dos Goytacazes - RJ.

respectivamente. Os dados climáticos referências da região estão apresentados na Tabela 1.

A análise do solo, por ocasião do plantio, apresentava as seguintes características nas camadas de 0 a 20 e 20 a $40 \mathrm{~cm}$, respectivamente: $\mathrm{pH} \mathrm{em} \mathrm{H}_{2} \mathrm{O}(1: 2,5)$ $=5,6$ e 5,$4 ; 21$ e $6 \mathrm{mg} \mathrm{kg}^{-1}$ de $\mathrm{P}$ (Mehlich - 1); 20 e 12 $\mathrm{mmol}_{\mathrm{c}} \mathrm{kg}^{-1}$ de Ca; 12 e $8 \mathrm{mmol}_{\mathrm{c}} \mathrm{kg}^{-1}$ de $\mathrm{Mg} ; 0,8$ e 0,3 $\mathrm{mmol}_{\mathrm{c}} \mathrm{kg}^{-1}$ de K; 0,3 e 0,3 $\mathrm{mmol}_{\mathrm{c}} \mathrm{kg}^{-1}$ de Na; 0 e $0 \mathrm{mmol}_{\mathrm{c}}$ $\mathrm{kg}^{-1}$ de Al; 3,3 e $23 \mathrm{mmol}_{\mathrm{c}} \mathrm{kg}^{-1}$ de $\mathrm{H}+\mathrm{Al} ; 6$ e $4 \mathrm{~g} \mathrm{~kg}^{-1} \mathrm{de}$ carbono; 1,25 e 1,3 dS $\mathrm{m}^{-1}$ de condutividade elétrica; 240 e $200 \mathrm{~g} \mathrm{~kg}^{-1}$ de areia fina; 520 e $460 \mathrm{~g} \mathrm{~kg}^{-1}$ de areia grossa; 30 e $30 \mathrm{~g} \mathrm{~kg}^{-1}$ de silte; 210 e $310 \mathrm{~g} \mathrm{~kg}^{-1}$ de argila.

A água utilizada na irrigação apresentava, em fev./96 e ago./97, respectivamente, as seguintes características químicas: $\mathrm{pH}=6$ e 4,5; 0,75 e 0,66 dS $\mathrm{m}^{-1}$ de condutividade elétrica; 236 e $167 \mathrm{mg} \mathrm{L}^{-1} \mathrm{de}$ cloreto; 20 e $5 \mathrm{mg} \mathrm{L}^{-1}$ de Ca; 25 e $15 \mathrm{mg} \mathrm{L}^{-1}$ de Mg; 4 e $4,5 \mathrm{mg} \mathrm{L}^{-1}$ de $\mathrm{K} ; 45$ e $80 \mathrm{mg} \mathrm{L}^{-1}$ de $\mathrm{Na}$. A água foi classificada como C2S1 (Bernardo, 1995) e, sendo assim, pode ser usada para plantas com razoável tolerância a sais, sempre que o solo permitir um grau moderado de lixiviação, e com pequena possibilidade de elevar o $\mathrm{Na}$ trocável no solo a níveis perigosos.

O delineamento experimental adotado foi em blocos casualizados, em esquema fatorial $4 \times 6$, com três repetições. Os tratamentos utilizados corresponderam a quatro doses de nitrogênio $(50,250,450$ e $650 \mathrm{~g}$ por planta por ano de $\mathrm{N}$ ), na forma de uréia, sob seis lâminas de irrigação $(0,25,50,75,100$ e $125 \%$ da evapotranspiração de referência - ETo), que corresponderam a lâminas totais de água (irrigação + precipitação efetiva entre mar./96 e jun./97) a 826, 1.041, $1.195,1.293,1.481$ e $1.733 \mathrm{~mm}$ de água, 
respectivamente. As parcelas foram constituídas por três fileiras com 24 plantas, em espaçamento de $3 \times 2$ metros, sendo que as seis plantas centrais foram consideradas úteis.

Todos os tratamentos receberam uma dose, por cova antes do plantio, de $35 \mathrm{~g}$ de $\mathrm{P}$, na forma de superfosfato simples, $25 \mathrm{~g}$ de $\mathrm{K}$, na forma de cloreto de potássio, e $50 \mathrm{~g}$ de FTE-BR12. Foram aplicados $10 \mathrm{e}$ 16,6 g planta $^{-1}$ de N e K, respectivamente, aos 30, 60 e 90 dias após o plantio. Os adubos, em cobertura, foram aplicados numa faixa de, aproximadamente, 30 a $40 \mathrm{~cm}$ distante do colo da planta, espalhados numa faixa de 20 a $30 \mathrm{~cm}$ de largura ao redor da planta. As doses de N, correspondentes aos tratamentos, foram divididas em 10 parcelas iguais durante o ano, entre abr./96 e abr./97, omitindo-se as aplicações nos meses de jul./96 e jan./ 97. Por ocasião da aplicação do adubo nitrogenado, aplicou-se uma dose constante de $50 \mathrm{~g}_{\text {planta }}{ }^{-1}$ de K, totalizando $500 \mathrm{~g}$ por planta por ano de $\mathrm{K}$.

Utilizaram-se mudas provenientes de sementes do maracujazeiro amarelo (Passiflora edulis f. flavicarpa) selecionadas em plantios na região Norte do Estado do Rio de Janeiro. O plantio foi realizado em dezembro de 1995 e as plantas foram conduzidas no sistema de espaldeira vertical, com um fio de arame, a 1,8 m de altura em relação ao nível do solo. Utilizaram-se, em algumas épocas, preventivamente, pulverizações com fungicidas a base de Oxicloreto de Cobre para controle de algumas doenças, como a bacteriose e a verrugose.

Nos tratamentos com irrigação, a água foi aplicada, inicialmente, através de um sistema de gotejamento por tubogotejador. Em set./96, trocou-se o sistema de irrigação por outro com gotejadores autocompensantes do tipo "Katif", com vazão de 3,75 $L h^{-1}$. O controle do volume aplicado por parcela foi feito através de hidrômetros instalados nas linhas de distribuição do sistema. Um tanque classe $\mathrm{A}$, com o qual foi determinado a ETo, e um pluviômetro foram instalados na área, o que permitiu quantificar o volume de água a ser aplicado diariamente na cultura. Utilizou-se um turno de rega de 2 dias.

A análise da composição mineral das plantas foi feita através de amostragens foliares coletadas em períodos bimestrais entre abril de 1996 e maio de 1997. Coletaram-se, por parcela útil, para análise, 20 folhas recém-maduras, sem pecíolo, e que continham nas suas axilas um botão floral próximo da antese, sendo, normalmente, a $4^{\text {a }}$ ou $5^{\mathrm{a}}$ folha a partir do ápice do ramo (Malavolta et al., 1989).

Após a coleta, as folhas foram acondicionadas em sacos de papel e limpas com algodão embebido em água deionizada. Após estes procedimentos, as folhas foram secas em estufa com circulação forçada de ar à temperatura de $70^{\circ} \mathrm{C}$, durante 48 horas. Após a secagem, o material foi triturado em moinho tipo Wiley com peneira de 20 mesh e armazenado em frascos hermeticamente fechados.
O N orgânico (Norg) foi determinado pelo método de Nessler (Jackson, 1965), após submeter o material vegetal à oxidação pela digestão sulfúrica $\left(\mathrm{H}_{2} \mathrm{SO}_{4}\right.$ e $\left.\mathrm{H}_{2} \mathrm{O}_{2}\right)$. O P, determinado colorimetricamente pelo método do molibdato, $0 \mathrm{~K}$ e $\mathrm{Na}$, por espectrofotometria de emissão de chama, foram determinados no extrato obtido a partir da digestão sulfúrica. $\mathrm{Ca}, \mathrm{Mg}, \mathrm{Zn}, \mathrm{Mn}$, Fe e Cu foram quantificados, após oxidação do material vegetal pela digestão nitroperclórica $\left(\mathrm{HNO}_{3}\right.$ e $\left.\mathrm{HClO}_{4}\right)$, por espectrofotometria de absorção atômica. O S, utilizando também o extrato proveniente da digestão nitro-perclórica, foi determinado por turbidimetria do sulfato. $\mathrm{O} \mathrm{Cl}$ e $\mathrm{O} \mathrm{NO}_{3}^{-}$foram determinado através de dosagem por titulação com $\mathrm{AgNO}_{3}$ e o método de ultravioleta (Cawse, 1967), respectivamente, após submeter o tecido vegetal a banho-maria por uma hora. O B foi determinado, colorimetricamente, pela azometina $\mathrm{H}$, após incineração em mufla.

Para o fator época de coleta de folhas compararam-se as médias pelo teste de Tukey a $5 \%$, enquanto para todos os outros fatores utilizou-se análise de regressão polinomial, teste $\mathrm{F}$ da análise de variância da regressão e coeficientes do modelo estatisticamente significativos e maior $\mathrm{R}^{2}$. As análises estatísticas foram efetuadas adotando-se os níveis de significância de $1 \%$ $\left(^{* *}\right), 5 \%\left(^{*}\right)$ e $10 \%\left({ }^{\wedge}\right)$.

\section{RESULTADOS E DISCUSSÃO}

Os teores foliares dos nutrientes apresentados nas Tabelas 2 e 3 correspondem, nas diversas épocas, àqueles obtidos no tratamento que proporcionou a máxima produtividade de frutos $\left(41,3 \mathrm{t} \mathrm{ha}^{-1} \mathrm{ano}^{-1}\right)$ no maracujazeiro amarelo e que correspondeu à aplicação de $250 \mathrm{~g}$ por planta por ano de $\mathrm{N}$ sob uma lâmina de irrigação de $75 \%$ da ETo, ou uma lâmina total de água (precipitação efetiva + irrigação), entre março de 1996 e junho de 1997, igual a $1.293 \mathrm{~mm}$. Houve grande variação entre as diversas épocas de coleta de folhas, fato também observado na Austrália, no campo, por Menzel et al. (1993).

Os valores dos nutrientes analisados estão dentro das faixas consideradas adequadas por Robinson (1986) e Malavolta et al. (1989), com exceções para o $\mathrm{K}$, o Ca, nas épocas compreendidas entre abr./96 e mar./ 97 (Tabela 2) e o Mn em todas as épocas (Tabela 3), que estão bem abaixo da faixa considerada adequada por Malavolta et al. (1989). Entretanto, não foram observados, no campo, sintomas de deficiências destes elementos.

Os teores de $\mathrm{P}$ na matéria seca foliar não foram afetados pelo adubo nitrogenado nem pela irrigação. Houve apenas variação entre as diversas épocas de coleta de folhas (Tabela 2). A média geral observada foi igual a $3,16 \mathrm{~g} \mathrm{~kg}^{-1}$ de $\mathrm{P}$ na matéria seca foliar, com uma variação entre 2,58 e $3,85 \mathrm{~g} \mathrm{~kg}^{-1}$, sendo que estes 
Tabela 2 - Teores de macronutrientes na matéria seca foliar do maracujazeiro amarelo, em diferentes épocas, no tratamento em que se obteve a máxima produtividade de frutos.

\begin{tabular}{llllllll}
\hline época & Norg & $\mathrm{NO}_{3}^{-}$ & $\mathrm{P}$ & $\mathrm{K}$ & $\mathrm{Ca}$ & $\mathrm{Mg}$ & $\mathrm{S}$ \\
\hline & - & - & - & - \\
abr./96 & $51,7 \mathrm{ab}$ & $1,64 \mathrm{~b}$ & $3,03 \mathrm{bc}$ & $23,6 \mathrm{c}$ & $9,25 \mathrm{bc}$ & $2,32 \mathrm{~cd}$ & $2,98 \mathrm{c}$ \\
jun./96 & $47,2 \mathrm{bc}$ & $1,63 \mathrm{~b}$ & $3,26 \mathrm{abc}$ & $26,6 \mathrm{bc}$ & $8,24 \mathrm{bc}$ & $2,23 \mathrm{~d}$ & $3,20 \mathrm{c}$ \\
set./96 & $49,6 \mathrm{~b}$ & $1,83 \mathrm{~b}$ & $3,50 \mathrm{ab}$ & $25,7 \mathrm{c}$ & $6,13 \mathrm{c}$ & $2,69 \mathrm{bcd}$ & $3,57 \mathrm{bc}$ \\
nov./96 & $40,8 \mathrm{c}$ & $1,66 \mathrm{~b}$ & $2,58 \mathrm{c}$ & $24,2 \mathrm{c}$ & $12,2 \mathrm{ab}$ & $2,89 \mathrm{bcd}$ & $3,69 \mathrm{bc}$ \\
jan./97 & $41,3 \mathrm{c}$ & $1,51 \mathrm{~b}$ & $2,84 \mathrm{bc}$ & $23,2 \mathrm{c}$ & $9,73 \mathrm{bc}$ & $3,01 \mathrm{bc}$ & $3,43 \mathrm{bc}$ \\
mar.197 & $46,4 \mathrm{bc}$ & $1,77 \mathrm{~b}$ & $3,09 \mathrm{bc}$ & $32,9 \mathrm{ab}$ & $10,6 \mathrm{abc}$ & $3,22 \mathrm{~b}$ & $3,96 \mathrm{ab}$ \\
mai./97 & $58,1 \mathrm{a}$ & $2,24 \mathrm{a}$ & $3,85 \mathrm{a}$ & $38,0 \mathrm{a}$ & $14,4 \mathrm{a}$ & $4,28 \mathrm{a}$ & $4,64 \mathrm{a}$ \\
\hline Média & 47,9 & 1,75 & 3,16 & 27,7 & 10,1 & 2,95 & 3,64 \\
\hline
\end{tabular}

Em cada coluna, médias seguidas pela mesma letra não diferem pelo teste de Tukey a $5 \%$.

Tabela 3 - Teores de $\mathrm{Na}$ e de micronutrientes na matéria seca foliar do maracujazeiro amarelo, em diferentes épocas, no tratamento em que se obteve a máxima produtividade de frutos.

\begin{tabular}{|c|c|c|c|c|c|c|c|}
\hline época & $\mathrm{Na}$ & $\mathrm{Cl}$ & $\mathrm{Fe}$ & $\mathrm{Zn}$ & $\mathrm{Mn}$ & $\mathrm{B}$ & $\mathrm{Cu}$ \\
\hline & \multicolumn{2}{|c|}{-- } & 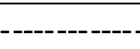 & --.-- & $\mathrm{mg} \mathrm{kg}^{1}$ & 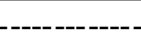 & 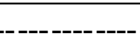 \\
\hline abr./96 & $2,18 b c$ & $22,0 \mathrm{~b}$ & $175 b$ & $36,5 \mathrm{a}$ & $75,9 a b$ & $32,9 \mathrm{abc}$ & $10,4 a$ \\
\hline jun./96 & $1,22 \mathrm{~cd}$ & $16,6 \mathrm{bc}$ & $120 \mathrm{bc}$ & $21,8 \mathrm{~b}$ & $75,5 \mathrm{ab}$ & $24,0 \mathrm{bc}$ & $6,90 \mathrm{a}$ \\
\hline set./96 & $0,77 \mathrm{~d}$ & $13,1 \mathrm{c}$ & $82 \mathrm{c}$ & $28,6 a b$ & $62,0 \mathrm{bc}$ & $16,8 \mathrm{c}$ & $234 \mathrm{a}$ \\
\hline nov./96 & $2,02 \mathrm{c}$ & $23,4 \mathrm{~b}$ & $87 \mathrm{c}$ & $21,1 \mathrm{~b}$ & $94,5 \mathrm{a}$ & $34,1 \mathrm{ab}$ & $5,72 \mathrm{a}$ \\
\hline jan./97 & $3,53 \mathrm{a}$ & $21,3 b$ & $160 \mathrm{~b}$ & $24,5 b$ & $44,4 \mathrm{c}$ & 46,6 a & $180 \mathrm{a}$ \\
\hline mar. 197 & $1,99 \mathrm{c}$ & $22,8 b$ & $117 \mathrm{bc}$ & $27,9 \mathrm{~b}$ & $69,9 a b c$ & $48,9 a$ & $4,40 \mathrm{a}$ \\
\hline mai./97 & $3,26 a b$ & 32,4 a & $246 a$ & $24,6 b$ & $77,0 \mathrm{ab}$ & $43,0 \mathrm{a}$ & 3,97 a \\
\hline Média & 2,14 & 21,7 & 141 & 26,4 & 71,3 & 35,2 & 63,6 \\
\hline
\end{tabular}

Em cada coluna, médias seguidas pela mesma letra não diferem pelo teste de Tukey a $5 \%$.

valores estão dentro da faixa considerada adequada por Robinson (1986) e abaixo daquela citada como adequada por Malavolta et al. (1989). Entretanto, não foram observados, no campo, sintomas de deficiência deste nutriente.

No caso do $\mathrm{P}$ e $\mathrm{K}$, os resultados encontrados estão dentro ou acima das faixas verificadas, no campo, por Menzel et al. (1993). Os resultados médios encontrados para o $\mathrm{N}$ estão dentro das faixas obtidas por Haag et al. (1973) e Menzel et al. (1993) e daquela considerada como adequada por Malavolta et al. (1989). Nos meses de novembro e janeiro, período de picos de florescimento e frutificação, os resultados encontrados para o $\mathrm{N}$ estão abaixo da faixa considerada adequada por Robinson (1986).

Para o K, verificou-se elevação acentuada nos teores foliares nos últimos meses de coleta (Tabela 1). Este fato deve ter ocorrido devido aos possíveis incrementos deste elemento no solo, em função da aplicação constante de cloreto de potássio $(\mathrm{KCl})$. Também para $\mathrm{Ca}, \mathrm{Mg}$ e $\mathrm{S}$, se verificou uma elevação crescente nos teores foliares com o aumento da idade da planta
Os teores médios de $\mathrm{NO}_{3}^{-}$variaram entre $1,51 \mathrm{e}$ $2,24 \mathrm{~g} \mathrm{~kg}^{-1}$ na matéria seca foliar do maracujazeiro amarelo (Tabela 2), entretanto, não foram encontrados na literatura resultados com o maracujazeiro, para possíveis comparações. Jones Jr. et al. (1991) afirmam que, para a maioria das culturas, teores de nitrato entre 1,5 e $2 \mathrm{~g} \mathrm{~kg}^{-1}$ de $\mathrm{NO}_{3}^{-}$na matéria seca de pecíolos maduros ou ramos é o suficiente para se obter altas produções. Observou-se um aumento significativo nos teores de $\mathrm{NO}_{3}^{-}$devido ao incremento da adubação nitrogenada, constatou-se, porém, que esta elevação foi muito pequena (Tabela 4).

A aplicação de $\mathrm{N}$ no solo elevou, de forma linear, os teores de Norg na matéria seca foliar do maracujazeiro (Tabela 4). O efeito linear não foi observado apenas nas duas primeiras épocas de coleta de folhas, o que pode ser devido à pequena área de solo explorada pelas raízes, associada à faixa de aplicação do adubo, normalmente 30 a $40 \mathrm{~cm}$ distante do colo da planta. $O$ acréscimo nos teores foliares de $\mathrm{N}$ variou, entre a menor e a maior dose de adubo nitrogenado, de $17 \%$, no mês de janeiro/97, a $3 \%$, no mês de maio/97. Não houve efeito da irrigação nos teores foliares de Norg e $\mathrm{NO}_{3}$. 
Tabela 4 - Equações ajustadas para os teores de Norg e $\mathrm{NO}_{3}^{-}$na matéria seca foliar do maracujazeiro amarelo, em função de doses de $\mathrm{N}$ (g por planta por ano) em diferentes épocas de coleta das folhas.

\begin{tabular}{|c|c|c|}
\hline Época de coleta & Equação ajustada para o Norg & Equação ajustada para o $\mathrm{NO}^{3-}$ \\
\hline & \multicolumn{2}{|c|}{ 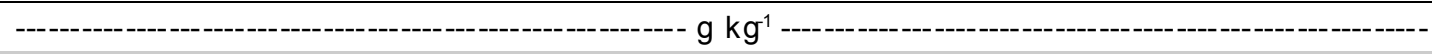 } \\
\hline $\mathrm{abr} / 96$ & $Y=51,9$ & $Y=1,74$ \\
\hline jun/96 & $Y=47,8$ & $Y=1,70$ \\
\hline set/96 & $Y=47,6+0,00547 N R^{2}=0,60^{*}$ & $Y=1,76$ \\
\hline nov/96 & $Y=37,4+0,00938 \mathrm{~N} \mathrm{R} R^{2}=0,93^{* *}$ & $Y=1,60+0,000452 N R^{2}=0,99^{*}$ \\
\hline jan/97 & $Y=38,5+0,01119 \mathrm{~N} R^{2}=0,99^{* *}$ & $Y=1,48+0,000208 N R^{2}=0,92^{\wedge}$ \\
\hline $\mathrm{mar} / 97$ & $Y=44,0+0,00837 N R^{2}=0,98^{* *}$ & $Y=1,66+0,000473 N R^{2}=0,81^{*}$ \\
\hline mai/97 & $Y=55,8+0,00329 N R^{2}=0,62^{\wedge}$ & $Y=2,05+0,000255 N R^{2}=0,84^{\wedge}$ \\
\hline
\end{tabular}

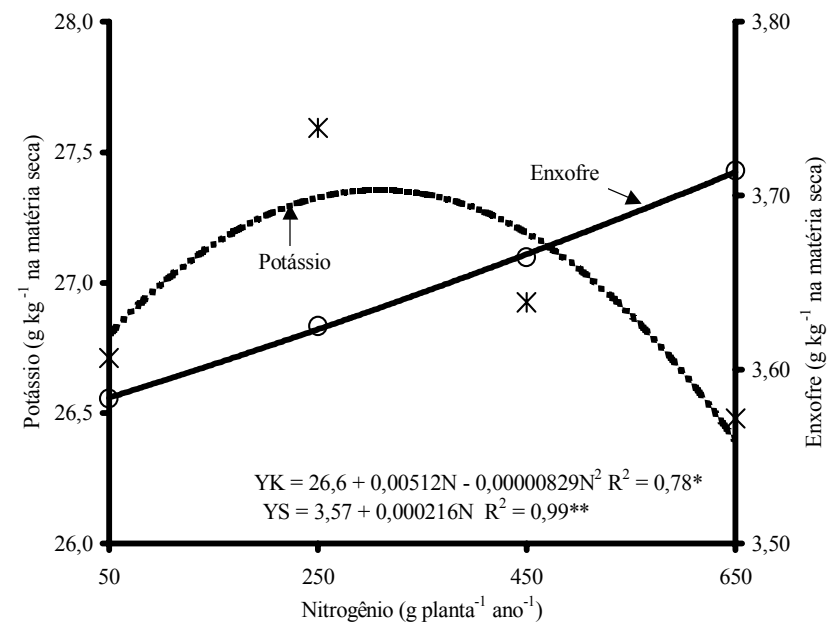

Figura 1 - Teores de $\mathrm{K}$ e S na matéria seca foliar do maracujazeiro amarelo, em função de doses de nitrogênio.

Para o potássio, houve efeito quadrático em função do aumento na adubação nitrogenada (Figura 1). Os teores foliares de $\mathrm{K}$ aumentaram quando se aplicaram até $308 \mathrm{~g}$ por planta por ano de $\mathrm{N}$, sendo observado um teor máximo de $28,1 \mathrm{~g} \mathrm{~kg}^{-1}$ de $\mathrm{K}$ na matéria seca. $\mathrm{O}$ incremento do adubo nitrogenado de 50 até $308 \mathrm{~g}$ por planta por ano de $\mathrm{N}$, levou a um aumento de $4,63 \%$ nos teores de K, num aumento que variou de 27,5 a $27,9 \mathrm{~g}$ $\mathrm{kg}^{-1}$ de $\mathrm{K}$ na matéria seca foliar do maracujazeiro amarelo.

Os teores de $\mathrm{S}$ aumentaram linearmente em função das doses de adubo nitrogenado utilizado (Figura 1). Entretanto, o aumento observado, apesar de significativo estatisticamente, foi muito pequeno, variando de 3,59 a $3,71 \mathrm{~g} \mathrm{~kg}^{-1}$ de $\mathrm{S}$ na matéria seca foliar entre a menor e a maior dose de $\mathrm{N}$ utilizada, ou seja, um aumento de apenas $3,23 \%$. Não houve influência da irrigação sobre os teores do $\mathrm{S}$.

A aplicação do adubo nitrogenado influenciou os teores de $\mathrm{Ca}$ e $\mathrm{Mg}$ na matéria seca foliar do maracujazeiro amarelo (Tabela 5). Em todas as épocas, os valores encontrados para o Ca estão bem abaixo daqueles observados, em condições de campo, por Menzel et al. (1993) e Haag et al. (1973) e abaixo da faixa considerada como adequada por Malavolta et al. (1989). Porém, além dos resultados obtidos para o Ca estarem na faixa considerada adequada por Robinson (1986), não foram verificados, no campo, sintomas de deficiência deste nutriente nas folhas e nos frutos. As lâminas de irrigação não afetaram os teores de Ca na matéria seca foliar.

Para o Ca observou-se um efeito quadrático nas análises dos meses de abr./96, nov.96 e mai./97, sendo que os teores de $\mathrm{Ca}$ atingiram os menores valores com doses correspondentes a 347, 431, $444 \mathrm{~g}$ por planta por ano de $\mathrm{N}$ nos três meses, respectivamente (Tabela 5). Nos meses de jun./96 e set./96 não houve mudança nos teores foliares do $\mathrm{Ca}$ em função do adubo nitrogenado. Foram observados decréscimos médios de $17 \%$ nos teores foliares de Ca nos meses de janeiro e março de 1997, quando comparadas as concentrações obtidas nos tratamentos com menores e aqueles com maiores doses de adubo nitrogenado. Decréscimos nos teores de cálcio na matéria seca foliar podem ser devidos à competição entre os íons $\mathrm{NH}_{4}^{+}$, proveniente da hidrólise da uréia, e o $\mathrm{Ca}^{++}$(Fernandes \& Rossiello, 1995 e Wilcox et al., 1977).

Os decréscimos observados nos teores foliares de $\mathrm{Mg}$, em função do aumento da adubação nitrogenada de 50 para $650 \mathrm{~g}$ por planta por ano de $\mathrm{N}$, variaram de $10 \%$ nos meses de novembro, janeiro e março a $15 \%$, no mês de maio (Tabela 5). Decréscimos nos teores foliares de Mg foram citados por Fernandes \& Rossiello (1995) e Wilcox et al. (1977).

Barker et al. (1967) e Maynard et al. (1965), citados por Castellane (1985), relatam que a deficiência de $\mathrm{K}$ é uma importante característica de toxidez de $\mathrm{NH}_{4}{ }^{+}$ em tomateiro. Contudo, os resultados verificados para o maracujazeiro amarelo sugerem que $\mathrm{Ca}$ e $\mathrm{Mg}$ sejam mais afetados pela adubação com uréia, cuja hidrólise gera $\mathrm{NH}_{4}^{+}$, estando, isto, de acordo com alguns autores (Castellane, 1985, Macklon \& Sim, 1980).

Com exceção das três primeiras épocas de análise de folhas, foram verificados decréscimos em torno de $16 \%$ nos teores foliares de $\mathrm{Cl}$ em função do aumento nas doses do adubo nitrogenado (Tabela 6), o que sugere uma competição entre os aniônios $\mathrm{NO}_{3}{ }^{-}$e $\mathrm{Cl}^{-}$. 
Tabela 5 - Equações ajustadas para os teores de Ca e Mg na matéria seca foliar do maracujazeiro amarelo, em função de doses de $\mathrm{N}$ (g por planta por ano) em diferentes épocas de coleta de folhas.

\begin{tabular}{|c|c|c|c|}
\hline Época de coleta & Equação ajustada para o $\mathrm{Ca}$ & \multicolumn{2}{|c|}{ Equação ajustada para o $\mathrm{Mg}$} \\
\hline & - & 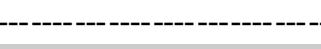 & --------------------- \\
\hline abr./96 & $Y=10,3-0,0110 N+0,0000159 N^{2} R^{2}=0,78^{\wedge}$ & $Y=2,49$ & \\
\hline jun./96 & $Y=8,89$ & $Y=2,26$ & \\
\hline set./96 & $Y=7,46$ & $Y=2,62$ & \\
\hline nov./96 & $Y=14,7-0,0181 \mathrm{~N}+0,000021 \mathrm{~N}^{2} R^{2}=0,98^{*}$ & $Y=2,85-0,00043 \mathrm{~N}$ & $\mathrm{R}^{2}=0,71^{*}$ \\
\hline jan./97 & $Y=11,1-0,0027 \mathrm{~N}$ & $Y=3,22-0,00049 \mathrm{~N}$ & $\mathrm{R}^{2}=0,80^{*}$ \\
\hline mar./97 & $Y=12,4-0,0032 \mathrm{~N}$ & $Y=3,50-0,00053 \mathrm{~N}$ & $\mathrm{R}^{2}=0,76^{*}$ \\
\hline mai./97 & $Y=16,9-0,0142 N+0,000016 N^{2} R^{2}=0,91^{\wedge}$ & $Y=4,42-0,00093 \mathrm{~N}$ & $R^{2}=0,95^{* *}$ \\
\hline
\end{tabular}

Tabela 6 - Equações ajustadas para os teores de $\mathrm{Cl}, \mathrm{Mn}$ e B na matéria seca foliar do maracujazeiro amarelo, em função de doses de $\mathrm{N}$ (g por planta por ano) em diferentes épocas de coleta das folhas.

\begin{tabular}{|c|c|c|c|}
\hline $\begin{array}{l}\text { Época de } \\
\text { coleta }\end{array}$ & $\begin{array}{c}\text { Equação ajustada } \\
\text { para o } \mathrm{Cl}\end{array}$ & $\begin{array}{c}\text { Equação ajustada } \\
\text { para o } \mathrm{Mn}\end{array}$ & $\begin{array}{c}\text { Equação ajustada } \\
\text { para o B }\end{array}$ \\
\hline & - g kg & 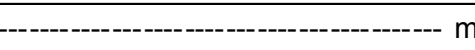 & - \\
\hline abr./96 & $Y=19,6$ & $Y=53,8$ & $Y=45,8$ \\
\hline jun./96 & $Y=15,5$ & $Y=57,3$ & $Y=29,5$ \\
\hline set./96 & $Y=14,7$ & $Y=52,5$ & $Y=19,2$ \\
\hline nov./96 & $Y=23,2-0,0060 N \quad R^{2}=0,98^{*}$ & $Y=59,2+0,0474 N \quad R^{2}=0,85^{*}$ & $Y=36,8-0,0127 N \quad R^{2}=0,80^{* *}$ \\
\hline jan./97 & $Y=23,5-0,0067 N \quad R^{2}=0,98^{*}$ & $Y=35,2+0,0240 N \quad R^{2}=0,90^{\wedge}$ & $Y=49,2-0,0207 N \quad R^{2}=0,90^{* *}$ \\
\hline mar./97 & $Y=25,0-0,0063 N \quad R^{2}=0,90^{*}$ & $Y=48,1+0,0539 N R^{2}=0,96^{* *}$ & $Y=52,9-0,0144 N \quad R^{2}=0,89^{* *}$ \\
\hline mai./97 & $Y=34,2-0,0092 N \quad R^{2}=0,97^{*}$ & $Y=53,7+0,0591 \mathrm{~N} R^{2}=0,99^{* *}$ & $Y=40,1-0,0062 N \quad R^{2}=0,95^{\wedge}$ \\
\hline
\end{tabular}

Houve elevação da concentração de manganês nas folhas do maracujazeiro amarelo com o aumento da dose do fertilizante nitrogenado. Na Tabela 6 verifica-se que apenas nas três primeiras épocas de análise não foram observados efeito da adubação nitrogenada sobre o teor foliar de Mn. Foram observadas elevações, em função do aumento na adubação nitrogenada de 50 para $650 \mathrm{~g}$ por planta por ano de N, que variaram de $40 \%$, no mês de jan./ 97, a $64 \%$, em mar./97.

Entretanto, apesar das alterações nos teores foliares de $\mathrm{Mn}$, decorrentes da adubação nitrogenada, os valores observados neste experimento estiveram bem abaixo das faixas encontradas por diversos pesquisadores e, em algumas épocas, abaixo da faixa considerada como adequada por Robinson (1986). Não foram observados, nas plantas, sintomas de deficiência deste nutriente. $\mathrm{O}$ aumento nos teores foliares de $\mathrm{Mn}$ em função do adubo nitrogenado pode está de acordo com a característica do elemento no solo, que tende a aumentar sua solubilidade em função do abaixamento do $\mathrm{pH}$, provocado pelo adubo utilizado.

O aumento nas doses do nitrogênio provocaram decréscimos nos teores do boro nas folhas do maracujazeiro amarelo (Tabela 6 ). Foi verificada influência do adubo nitrogenado na concentração de $B$ na matéria seca foliar do maracujazeiro amarelo a partir de set./96. Em cada época de avaliação observaram-se decréscimos que variaram de 9 a $24 \%$ nos teores de $B$ entre a menor e maior dose de adubo nitrogenado. Esta diminuição nos teores foliares de B pode ser devida à inibição promovida pelos íons $\mathrm{NO}_{3}{ }^{-} \mathrm{e}_{4}{ }^{+}$sobre a absorção do $\mathrm{H}_{2} \mathrm{BO}_{3}^{-}$(Malavolta et al., 1989). Resende et al. (1997) observaram, em folhas de milho, acréscimos nos teores foliares de B com o aumento nas doses de nitrogênio. A utilização da irrigação não influenciou os teores de $B$ na folha do maracujazeiro amarelo.

A adubação nitrogenada e as lâminas de irrigação não exerceram influência sobre os teores foliares de ferro, zinco e cobre, que apresentaram médias de $141,26,4$ e $63,6 \mathrm{mg} \mathrm{kg}^{-1}$ de $\mathrm{Fe}$, Zn e Cu na matéria seca, respectivamente (Tabela 3). É importante salientar que as concentrações encontradas para o cobre nos meses de set./96 e jan./97 estão muito acima daquelas concentrações consideradas adequadas por vários pesquisadores e foram devido à aplicações preventivas de fungicidas que continham na sua composição este elemento químico.

As lâminas de irrigação provocaram aumento nos teores de $\mathrm{Cl}$ e de $\mathrm{Na}$ no limbo foliar do maracujazeiro amarelo (Figura 2). Verificaram-se aumentos em torno de $20 \%$ nos teores foliares de $\mathrm{Cl}$ em função do acréscimo nas lâminas de irrigação de 0 para $125 \%$ da ETo. Houve aumento linear nos teores de sódio nas folhas do maracujazeiro amarelo com o incremento nas lâminas de irrigação, havendo uma variação de 1,93 até $2,29 \mathrm{~g} \mathrm{~kg}^{-1}$ de $\mathrm{Na}$ na matéria seca foliar, o que representou uma elevação de $19 \%$. As presenças do cloreto e de sódio na água de irrigação foram, certamente, a principal causa para o aumento verificado nos teores foliares destes elementos, com o aumento da irrigação. 


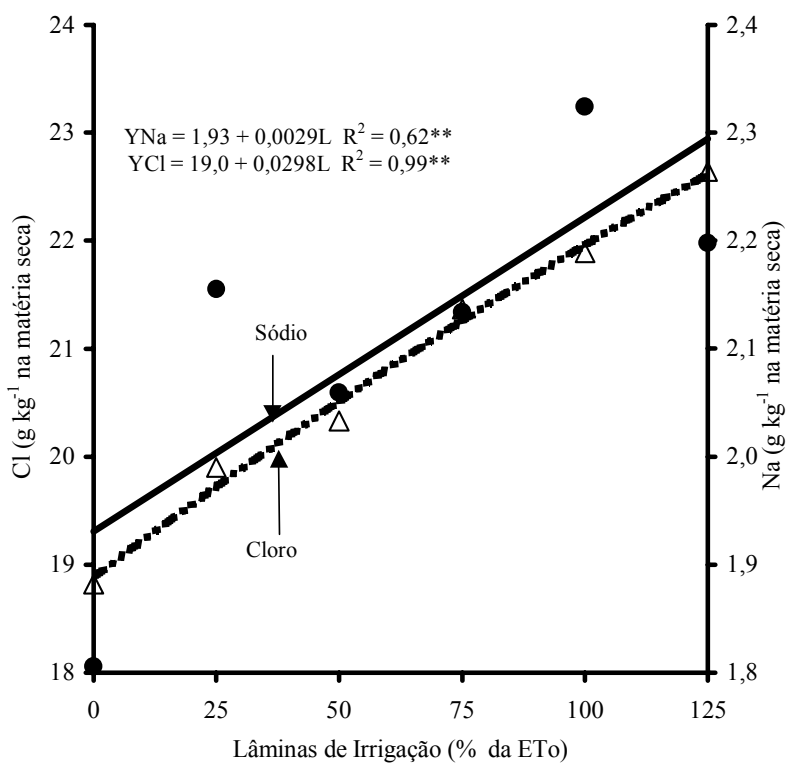

Figura 2 - Teores de $\mathrm{Cl}$ e $\mathrm{Na}$ na matéria seca foliar do maracujazeiro amarelo, em função de lâminas de irrigação.

\section{CONCLUSÕES}

Os teores dos macronutrientes na matéria seca foliar, na maior produtividade de frutos, variaram, entre as diferentes épocas do ano, de 40,8 a $58,1 \mathrm{~g} \mathrm{~kg}^{-1}$ de $\mathrm{N}$, 1,51 a $2,24 \mathrm{~g} \mathrm{~kg}^{-1}$ de $\mathrm{NO}_{3}^{-}, 2,58$ a $3,85 \mathrm{~g} \mathrm{~kg}^{-1}$ de $\mathrm{P}, 23,2$ a $38 \mathrm{~g} \mathrm{~kg}^{-1}$ de K, 6,13 a 14,4 $\mathrm{g} \mathrm{kg}^{-1}$ de Ca, 2,23 a 4,28 g $\mathrm{kg}^{-1}$ de $\mathrm{Mg}$ e 3,2 a $4,64 \mathrm{~g} \mathrm{~kg}^{-1}$ de S; Os teores dos micronutrientes e de Na na matéria seca foliar, na maior produtividade de frutos, variaram, entre as diferentes épocas do ano, de 13,1 a $32,4 \mathrm{~g} \mathrm{~kg}^{-1}$ de $\mathrm{Cl}, 77$ a 246 $\mathrm{mg} \mathrm{kg}^{-1}$ de $\mathrm{Fe}, 21,1$ a $31,8 \mathrm{mg} \mathrm{kg}^{-1}$ de $\mathrm{Zn}, 44,4$ a 94,5 $\mathrm{mg} \mathrm{kg}^{-1}$ de $\mathrm{Mn}, 34,1$ a $48,9 \mathrm{mg} \mathrm{kg}^{-1}$ de $\mathrm{B}, 4,41$ a $8,47 \mathrm{mg}$ $\mathrm{kg}^{-1}$ de $\mathrm{Cu}$ e de 0,77 a $3,53 \mathrm{~g} \mathrm{~kg}^{-1}$ de $\mathrm{Na}$. A adubação nitrogenada elevou os teores foliares de $\mathrm{N}, \mathrm{K}, \mathrm{S}$ e $\mathrm{Mn}$ e decresceu os de $\mathrm{Ca}, \mathrm{Mg}, \mathrm{Cl}$ e $\mathrm{B}$. A irrigação elevou os teores de $\mathrm{Cl}$ e de $\mathrm{Na}$ nas folhas e não influenciou nos teores foliares dos demais nutrientes avaliados.

\section{REFERÊNCIAS BIBLIOGRÁFICAS}

AGUIRRE, A.C.P. Nutrição mineral do maracujá amarelo (Passiflora edulis Sims f. flavicarpa). Piracicaba, 1977. 116p. Dissertação (Mestrado) - Escola Superior de Agricultura "Luiz de Queiroz", Universidade de São Paulo.

BERNARDO, S. Manual de irrigação. Viçosa: Imprensa Universitária, 1995. 657p.

CASTELLANE, P.D. Constatação e interpretação fisiológica de diferenças de susceptibilidade de cultivares de tomateiro (Lycopersicon esculentum, Mill.) à podridão apical. Viçosa, 1985. 183p. Tese (Doutorado) - Universidade Federal de Viçosa.
CAWSE, P.A. The determination of nitrate in soil solution by ultraviolet spectrophotometry. Analyst, v.9, p.309-313, 1967.

FERNANDES, M.S.; ROSSIELLO, R.O.P. Mineral nitrogen in plant physiology and plant nutrition. Critical Reviews in Plant Sciences, v.14, p.111-148, 1995.

HAAG, H.P.; OLIVEIRA, G.D.; BORDUCCHI, A.S.; SARRUGE, J.R. Absorção de nutrientes por duas variedades de maracujá. Anais da ESALQ, v.30, p.267-279, 1973.

JACKSON, M.L. Soil chemical analysis. New Jersey: Prentice Hall, 1965. 498p.

JONES JR., J.B.; WOLF, B.; MILLS, H.A. Plant analysis handbook: a practical sampling, preparation, analysis, and interpretation guide. Athens: Micro-Macro Publishing, 1991. 213p.

KLIEMANN, H.J.; CAMPELO JR., J.H.; AZEVEDO, J.A. de; GUILHERME, M.R.; GENÚ, P.J. de C. Nutrição mineral e adubação do maracujazeiro. In: HAAG, H.P. (Coord.) Nutrição mineral e adubação de frutíferas tropicais no Brasil. Campinas: Fundação Cargill, 1986. p.245-284.

MACKLON, A.E.S.; SIM, A. Eletrophysiological factors in the influence of nitrate and ammonium ions on calcium uptake and translocation in tomato plants. Physiologia Plantarum, v.49, p.449-454, 1980.

MALAVOLTA, E.; VITTI, G.C.; OLIVEIRA, S.A. de. Avaliação do estado nutricional das plantas: princípios e aplicações. Piracicaba: POTAFOS, 1989. 201p.

MENZEL, C.M.; HAYDON, G.E.; SIMPSON, D.R. Effect of nitrogen on growth and flowering of passionfruit (Passiflora edulis $\mathrm{f}$. edulis $\times$ P. edulis f. flavicarpa) in sand culture. Journal of Horticultural Science, v.66, p.689-702, 1991.

MENZEL, C.M.; HAYDON, G.E.; DOOGAN, V.J.; SIMPSON, D.R. New standard leaf nutrient concentrations for passionfruit based on seasonal phenology and leaf composition. Journal of Horticultural Science, v.68, p.215-230, 1993.

NATALE, W. Diagnose da nutrição nitrogenada e potássica em duas cultivares de goiabeira (Psidium guajava L.), durante três anos. Piracicaba, 1993. 145p. Tese (Doutorado) - Escola Superior de Agricultura "Luiz de Queiroz", Universidade de São Paulo.

RESENDE, G.M. de; SILVA, G.L. da; PAIVA, L.E.; DIAS, P.F.; CARVALHO, J.G. de. Resposta do milho (Zea mays L.) a doses de nitrogênio e potássio em solo da região de LavrasMG. III. Micronutrientes na parte aérea. Ciência e Agrotecnologia, v.21, p.58-70, 1997.

ROBINSON, J.B. Fruits, vines and nuts. In: REUTER, D.J.; ROBINSON, J.B. (Ed.) Plant analysis: an interpretation manual. Melbourne: Inkata Press, 1986. p.120-147.

THOMPSON, J.W. Effects of fertilizers and soil amendments on mineral constituents of maize. Soil Science, v.94, p.323-330, 1962.

WILCOX, G.E.; MITCHELL, C.A.; HOFF, J.E. Influence of nitrogen form on exudation rate, and ammonium, amide and cation composition of xylem exudate in tomato. Journal of the American Society for Horticulture Science, v.102, p.192196, 1977.

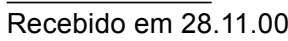

